\title{
РЕКОМЕНДАЦИИ ПО СОВЕРШЕНСТВОВАНИЮ ТЕКУЩЕЙ СИСТЕМЫ ВНУТРЕННЕГО ФИНАНСОВОГО КОНТРОЛЯ
}

\author{
(c) 2021 Петров A.M. \\ доктор экономических наук, профессор Департамента бизнес-аналитики \\ Финансовый университет при Правительстве Российской Федерации, Россия, Москва \\ E-mail:palmi@inbox.ru
}

Эффективное исполнение федеральных проектов, в части расходования выделенных на них средств, опирается на оперативный и превентивный инструментарий внутреннего финансового контроля. В статье даются рекомендации по совершенствованию текущей системы внутреннего финансового контроля

Ключевые слова: бюджетные нарушения, внутренний финансовый контроль, федеральный проект, отраслевой риск, ключевые индикаторы риска.

Предварительный и текущий контроль особенно важны не только для выявления ключевых нарушений расходования средств и иных неправомерных действий, но и также своевременного принятия решения по их устранению. Последующий контроль может лишь зафиксировать факт правонарушения, но не может обеспечить его устранение во время работы и освоения.

Для повышения результативности и целевого использования бюджетных средств, следует повышать важность внутреннего финансового контроля. С целью сделать контроль и аудит более эффективным и строгим, следует четко разделять процедуры каждого уровня проверки.

Можно дать следующие рекомендации по совершенствованию текущей системы внутреннего финансового контроля:

- осуществление и принятие соответствующих нормативно-правовых актов, закрепляющих ответственность за расходованием федеральных средств;

- доведение до субъектов своевременных ассигнований федерального бюджета;

- определение единых сроков сдачи у смежных по назначению федеральных проектов (Государственных программ и национальных проектов);

- обеспечение открытой и прозрачной информации по движению денежных средств, направленных на реализацию федеральных проектов;

- введение единой системы статистических количественных и качественных показателей контроля с их правовым закреплением.
Далее предложим рекомендации по организации эффективного внутреннего контроля:

1. Рекомендации по определению допустимости затрат.

Расходы должны быть согласованы и осуществляться в соответствии с утвержденными статьями бюджета. Любые изменения или отклонения от утвержденного бюджета и заявки на федеральный проект требуют предварительного одобрения со стороны государства.

При определении того, как субъект хозяйствования будет расходовать выделенные средства, менеджер проекта должен рассмотреть предполагаемые расходы, чтобы определить, является ли это допустимым использованием федеральных средств. Менеджер проекта должен учитывать эти факторы при принятии решения о допустимости, прежде чем эти средства будут потрачены на приобретение товара или услуги. Расходы являются допустимыми, если по своему характеру и сумме они не превышают тех расходов, которые были бы понесены благоразумным лицом при обстоятельствах, сложившихся на момент принятия решения об их возникновении [1]. Например, «допустимые расходы» означают, что соблюдаются разумные методы их расходования, а стоимость закупки сопоставима с рыночными ценами [3].

Факторы определения обоснованности затрат [3]: являются ли данные затраты необходимыми для эффективного осуществления федерального проекта в полном объеме; ограничения, налагаемые законодательством, требования нормативных актов, условия исполнения 
конкретного федерального проекта; цены на сопоставимые услуги и товары данного географического региона; осмотрительность, рациональность и добросовестность исполнительных лиц при исполнении обязанностей перед субъектом хозяйствования, коллегами, общественностью и правительством; существенность отклонения методов расходования субъектом хозяйствования средств от устоявшейся политики и практики, что может неоправданно завысить расходы на исполнение федерального проекта.

При определении того, являются ли те или иные затраты необходимыми, может быть учтено следующее: необходимы ли эти затраты для надлежащего и эффективного выполнения федерального проекта; независимо от того, указаны ли эти расходы в утвержденном бюджете или заявке; существует ли выгода, связанная с понесенными затратами; соответствуют ли затраты выявленным потребностям, определенным на основе их оценки; соответствуют ли затраты целям и задачам федерального проекта.

Расходы не могут быть отнесены на федеральный проект в качестве прямых расходов, если любые другие расходы, понесенные с той же целью в аналогичных обстоятельствах, были отнесены в качестве косвенных расходов на другой федеральный проект.

Все расходы должны быть надлежащим образом задокументированы, что определяется в соответствии с общепринятыми принципами бухгалтерского учета, если не предусмотрено иное. Они не включаются в качестве затрат, если конкретный федеральный проект не разрешает рассматривать федеральные расходы как таковые. Некоторые федеральные проекты требуют, чтобы субъект, не являющийся федеральным субъектом, вносил определенный объем нефедеральных ресурсов, чтобы иметь право на участие в федеральном проекте.

Субъекту хозяйствования следует быть «чистым» в отношении всех скидок, кредитов, надбавок, возмещений убытков и пр. В той мере, в какой такие «кредиты», относятся к федеральному проекту, они должны быть зачислены на федеральный проект либо в качестве сокращения расходов, либо в качестве денежного возмещения в зависимости от обстоятельств. Закупки товаров и услуг, оплачиваемые за счет средств федерального проекта, должны осуществляться за вычетом всех применимых скидок. Чтобы избежать получения «кредитов», когда льготы не возмещаются или не зачисляются на федеральный проект, личные компенсации не поощряются для покупок, сделанных с федеральными проектами.

Субъект хозяйствования может воспользоваться всеми скидками на оперативную оплату и все платежи, осуществляемые за счет средств федеральных проектов, должны обрабатываться через систему учета.

Следует выделить командировочные расходы на приобретение товаров, как частый вид затрат. Начисление командировочных расходов должно осуществляться на основе установленных норм затрат, суточных, пробега или на основе фактических понесенных затрат, а также на основе комбинации этих двух методов, при условии, что используемый метод применяется ко всей поездке, а не к отдельным дням поездки, и приводит к взиманию сборов, соответствующих тем, которые обычно разрешаются в аналогичных обстоятельствах в деятельности получателя, не финансируемой из федерального бюджета, и в соответствии с письменной политикой возмещения расходов на поездки получателя федеральных средств.

Командировочные расходы должны быть разумными и допустимыми, по ним должна быть представлена подтверждающая документация: во-первых, по участию физического лица в федеральном проекте; во-вторых, по согласованию с установленной политикой и бюджетом.

Для того чтобы определить, можно ли использовать федеральные средства для покупки конкретного товара, полезно ответить на следующие вопросы:

- Допустимы ли затраты в рамках соответствующего проекта?

- Соответствуют ли затраты утвержденному плану проекта и бюджету?

- Соответствуют ли затраты конкретным фискальным правилам проекта?

- Согласуется ли затраты?

- Соответствуют ли затраты конкретным условиям, предъявляемым к федеральному проекту?

На практике финансовому директору следует также рассмотреть вопрос о том, соответствуют ли затраты основным потребностям федерального проекта.

2. Рекомендации по управлению и контрольных мероприятий за расходованием денежных средств. 
Субъекту хозяйствования следует соблюдать применимые методы и процедуры оплаты, которые сводят к минимуму время, проходящее между переводом средств и их выплатой, в соответствии с законом. Процедура расходования средств из федеральных проектов начинается после первой выплаты из бюджета [1].

Сотруднику по вопросам кредиторской задолженности следует требовать возмещения фактических расходов, понесенных в рамках федеральных проектов на ежемесячной основе. После 20-го числа каждого месяца сотрудник по вопросам кредиторской задолженности должен рассматривать расходы по каждому федеральному проекту и определять, имеет ли субъект хозяйствования право на возмещение. Для целей документирования сотрудник по расчетам с кредиторской задолженностью вводит данные в систему учета за текущий год, распечатки ежемесячного запроса о выделении средств и любые дополнительные расчеты для определения сметной потребности на предстоящий месяц. Всё возмещение расходов основывается на фактических выплатах, а не на обязательствах. Обязательства должны возникать в период между датой начала и датой окончания федерального проекта. Этот период времени называется периодом исполнения, он прописан в проекте.

Федеральные проекты, управляемые государством, доступны для исполнения обязательств в течение года, на который государство выделяет эти средства.

3. Рекомендации по определению и контролю затрат труда и заработной платы.

Все сотрудники субъекта хозяйствования, которым полностью или частично выплачиваются федеральные средства, должны иметь конкретные документы, подтверждающие количество времени или труда, затраченного ими на исполнение обязанностей в рамках проекта. Начисления заработной платы по каждому из федеральных проектов должны основываться на отчетах, отражающих реально выполненную работу по проекту. Требования к записям в части начисления заработной платы по федеральным проектам [3]: они должны быть подтверждены внутренним финансовым контролем, обеспечивающим разумную уверенность в точности, допустимости и правильности их распределения; они должны быть отражены в официальных отчетах; они должны обоснованно и комплексно отражать деятельность, за которую участник проекта получает оплату; они должны быть осуществлены с учетом, установленных в учетной политике правил бухгалтерского учета; при их проведении должны быть соблюдены правила начисления и распределения заработной платы между конкретными видами деятельности и целями затрат.

4. Рекомендации по организации системы закупок. Субъект хозяйствования должен поддерживать следующие процедуры закупок.

Агентом по закупкам является финансовый директор и, таким образом, сохраняет за собой право рассматривать и утверждать все закупки, неся полную ответственность за закупки.

Каждая заявка на закупку должна содержать имя/номер поставщика, его месторасположение, количество, описание товара, цену единицы, сумму груза и код счета, который будет оплачиваться. Описание товара должно быть четким, для того чтобы надлежащим образом сообщить поставщику описание запрашиваемого товара и/или услуги, которая должна быть выполнена, и сроки поставки и/или завершения.

Директор по финансам и операциям должен рассмотреть заявку на закупку и, если нет ошибок, утвердить её, после этого она преобразуется в заказ на покупку. Заявки, содержащие ошибки, отправляются обратно для исправления.

В системе учета каждому запросу на закупку должен быть присвоен уникальный номер отслеживания, после утверждения и преобразования запроса в заказ на покупку. Хотя номер для каждого заказа на покупку уникален, все номера заказов на покупку рекомендуется начинать с цифр финансового года. Например, первый заказ на покупку, введенный в 2019 финансовом году, может быть пронумерован как 193-й, где «3» означает, что это заказ на покупку определенного отдела, например, материально-технического.

После утверждения заказа на покупку система должна сгенерировать копии печатного заказа на покупку. Копия поставщика отправляется ему по факсу и/или почтой. После получения товара или услуги копия платежного запроса направляется в финансовый отдел для оплаты.

Ответственный менеджер должен нести ответственность за следующее: координирование связи с продавцом исполнителем; оценку квалификации персонала по контракту на соответствие его требованиям; определение приемлемости отчетов и результатов, подготовленных 
подрядчиком; утверждение или отклонение запросов на оплату услуг подрядчика; поправки к контракту и их оформление в письменном виде, и утверждением финансовым директором.

5. Предложения по организации системы управления и контроля имущества.

Системой контроля, регулируемой в субъекте хозяйствования, обеспечиваются надлежащие гарантии в части предотвращения утраты, повреждения, кражи имущества. Для этого все имущество, приобретаемое для реализации продукта, должно пройти инвентаризацию, осуществляемую по всем активам субъекта хозяйствования. Например, в момент получения материалов, они должны проверяться, чтобы убедиться, что все заказанные материалы доставлены в хорошем состоянии и соответствуют заказу, размещенному через систему заказов на закупку. Товары должны инвентаризироваться в момент их распаковки, а учет запасов должен осуществляться отделом, ответственным за приобретенные товары. Все технологическое оборудование должно быть помечено номерами.

Оборудование должно использоваться в проекте, для которого оно было приобретено, до тех пор, пока это необходимо, независимо от того, продолжает ли проект поддерживаться государством. Во время использования оборудования в проекте, оно также будет предоставлено для использования в других проектах, которые в настоящее время или ранее поддерживались федеральным правительством, при условии, что такое использование не будет препятствовать работе над основным проектом. При условии, если оборудование больше не требуется для первоначального проекта, то оно может быть использовано в других видах деятельности.

\section{Библиографический список}

1. Петров А. М., Бурцева К. Ю. К вопросу организации внутреннего финансового контроля в рамках расходования средств на федеральные проекты // Экономические науки. - 2020. - № 188. - С. 113-119.

2. Петров А.М. Оперативный и превентивный инструментарий реализации внутреннего финансового контроля в рамках расходования средств на федеральные проекты // Экономические науки. - 2020. - № 185 . - С. 169-178.

3. INTERNAL CONTROL MANUAL FOR FEDERAL GRANTS [Электронный ресурc]. - URL: https://www.ipsk12.net/ cms/lib/MA02212674/ Centricity/Domain/275/IPS\%20MANUAL\%20FOR\%20FEDERAL\%20GRANTS-Final\%20 Version\%205.4.17.pdf (дата обращения: 10.03.2020).

4. Петрова О.А. «Бухгалтерский учет обеспечения исполнения контрактных обязательств в России» / Экономические науки 2021, № 9, стр. 232-234

5. Петрова О.А. «Цифровизация консолидированной финансовой отчетности в страховом бизнесе» / Экономические науки 2021, № 10

6. Петрова О.А. «Проблемы развития рынка факторинговых услуг» / Экономические науки 2021, № 10

7. Chen T.-C., Zhu W.-W., Jiao Z.-K., Petrov A.M. Creep-fatigue lifetime estimation of snagcu solder joints using an artificial neural network approach / Mechanics of Advanced Materials and Structures. 2021.

8. Shabbir M.S., Siddiqi A.F., Yapanto L.M., Tonkov E.E., Poltarykhin A.L., Pilyugina A.V., Petrov A.M., Foroughi A., Valiullina D.A. Closed-loop supply chain design and pricing in competitive conditions by considering the variable value of return products using the whale optimization algorithm / Sustainability. 2021. T. 13. № 12.

9. Kavitha M., Mahmoud Z.H., Kishore K.H., Petrov A.M., Lekomtsev A., Iliushin P., Zekiy A.O., Salmani M. Application of Steinberg model for vibration lifetime evaluation of SN-AG-CU-based solder joints in power semiconductors / IEEE Transactions on Components, Packaging and Manufacturing Technology. 2021. T. 11. № 3. C. 444-450.

10. Shnaider V.V., Pipko E.G., Petrov A.M. Current information needs of passenger and freight transportation enterprises in Russia / Вестник Национальной академии наук Республики Казахстан. 2020. № 4 (386). С. 348-353.

11. Petrov A., Tolmachev M., Shlychkov D., Basova M., Turishcheva T. Analysis of current trends of employment diversification at the international level: case study of pharmacy industry / Systematic Reviews in Pharmacy. 2020. T. 11. № 12. C. 1383-1390. 